DOI: https://doi.org/10.18309/anp.v51iesp.1517

\title{
NOTAS SOBRE CLARICE LISPECTOR E A TRADUÇÃO DA LITERATURA GÓTICA ANGLÓFONA
}

\section{NOTES ON CLARICE LISPECTOR AND THE TRANSLATION OF ANGLOPHONE GOTHIC LITERATURE}

\author{
Vanessa Lopes Lourenço Hanes \\ Universidade Federal Fluminense, Niterói, Rio de Janeiro, Brasil \\ vanessahanes@gmail.com
}

Resumo: Este texto analisa três traduções brasileiras de obras literárias góticas anglófonas feitas pela aclamada autora Clarice Lispector. Traduções de Tales of the Grotesque and Arabesque, de Edgar Allan Poe, The picture of Dorian Gray, escrito por Oscar Wilde, e Interview with the vampire, de autoria de Anne Rice, foram comparadas e contrastadas em busca de regularidades na abordagem de Lispector para a literatura gótica. Os achados demonstram que Lispector utilizou um registro alto em suas três traduções, uma abordagem que, surpreendentemente, pode refletir o cuidadoso uso de língua daquela autora na tradução de diferentes tipos de texto.

Palavras-chave: Clarice Lispector; Literatura gótica; Literatura traduzida

Abstract: This text analyzes three Brazilian translations of anglophone Gothic literature carried out by acclaimed author Clarice Lispector. Translations of Tales of the Grotesque and Arabesque, by Edgar Allan Poe, The picture of Dorian Gray by Oscar Wilde, and Interview with the vampire by Anne Rice were compared and contrasted in search of regularities in Lispector's approach to Gothic literature. The findings demonstrate that Lispector used high register in the three translations, an approach that, surprisingly, may reflect that author's careful use of language in the translation of different texts.

Keywords: Clarice Lispector; Gothic literature; Translated literature 
Não parece exagerado afirmar que a ilustre autora Clarice Lispector dispensa apresentações, particularmente em se tratando aqui de uma publicação nacional e voltada a acadêmicos da área de literatura. Seu merecido prestígio nos círculos literários brasileiros e mundiais e a admiração despertada pelas suas obras ainda nos bancos da escola nos são velhos conhecidos. E sua presença na academia brasileira enquanto a autora de riquíssimos objetos de pesquisa e reflexão já se estabeleceu há anos. Mas há uma outra Clarice que, para muitos, ainda carece de uma apresentação formal: a tradutora Clarice Lispector, cuja produção intelectual também foi considerável, mas que é compreensivelmente ofuscada pela faceta da Clarice autora.

A Clarice Lispector tradutora vem aos poucos sendo descoberta pela academia brasileira, particularmente nos últimos anos. Trabalhos como os de Gomes (2004), Ferreira (2013) e Queiroga (2014) demonstram que há um crescente interesse em trazer á tona esta importante faceta clariceana. Embora Ferreira (2013) chame a atenção para o fato de que no caso de Lispector havia um atrelamento entre o traduzir e o suprimento de suas necessidades financeiras, Gomes (2004) menciona o auto-declarado cuidado daquela autora com o fazer tradutório, o que nos parece atestar a relevância das análises destas traduções para uma melhor compreensão global do pensamento e do legado clariceanos.

A produção tradutória de Clarice Lispector provoca questionamentos já à primeira vista graças à sua diversidade: trata-se de uma combinação de obras originadas de diferentes línguas (majoritariamente inglês e francês), pertencentes a diferentes gêneros, e que vão desde escritos de autores de literatura canonizada até grandes best sellers da literatura de massa (a maioria das publicações encontradas, numericamente falando). Mas, mesmo diante desta ampla e aparentemente desconexa gama de textos, é possível detectar que muitas das obras traduzidas podem ser enquadradas em uma certa lógica temática. As obras detetivescas e os textos góticos, por exemplo, parecem ocupar lugar de destaque neste conjunto de escritos traduzidos.

A existência de uma associação entre o nome de Lispector e a tradução de gêneros textuais tradicionalmente atrelados ao mistério e ao terror não causa grande surpresa. Afinal, como relata o seu biógrafo Moser (2017), Clarice era frequentemente vista pela sociedade como uma bruxa, e tinha certa simpatia pelo ocultismo, como demonstram seu conhecido hábito de consultar cartomantes e o fato de ter sido uma convidada de honra no Primeiro Congresso Mundial de Bruxaria, realizado em 1975 na Colômbia (o que teve grande repercussão na mídia nacional e internacional). E estas afinidades se estendiam aos seus escritos: Clarice afirmou, por exemplo, que em seu conto $O$ ovo e a galinha há um toque de ocultismo. Aparentemente, portanto, a tradução de obras literárias góticas, objeto do presente artigo, acrescentariam e/ou iriam ao encontro desta persona construída (não se sabe se voluntária ou involuntariamente) por Clarice Lispector.

O que causou surpresa nesta pesquisa foi a descoberta de que, de acordo com buscas empreendidas em bases de dados online via Google Acadêmico, as associações entre Lispector e os escritos góticos são ainda um tema pouco explorado. Há alguns estudos como aquele de Prospero (2008), que analisa o medo nos contos da autora sob as perspectivas psicanalítica e filosófica, e o de Oliveira (2012), que aborda representações monstruosas em A paixão segundo G.H., mas aparentemente tratam-se ainda de explorações iniciais de uma temática com muitas potencialidades. E, no âmbito dos estudos tradutórios, ainda menos pode ser encontrado associando Clarice Lispector e o gênero gótico de modo específico.

É oportuno abrir aqui um parêntese para refletir brevemente sobre o que seria a literatura gótica. $\mathrm{O}$ fato é que, embora a literatura gótica seja tradicionalmente associada a 
elementos como representações do mal, o horror, a morte, o medo e a melancolia, conforme indica Mulvey-Roberts (1998) não há uma resposta fácil para especificar exatamente o que a determina. Aquela autora questiona se a literatura gótica seria definida por um tipo de enredo, de cenário, de discurso, de modo de representação, de convenções de caracterização, ou ainda por uma combinação de todos estes aspectos. Smith (2007) também problematiza o conceito da literatura gótica ao dizer que sua própria forma é gerada diferentemente em diferentes contextos sociais e nacionais. Ele traz, no entanto, uma didática explicação para a origem do termo em si, a qual ajuda a compreender a sua posterior aplicação na esfera literária:

\begin{abstract}
A palavra "gótico" significa coisas diferentes em diferentes contextos. Os godos foram uma tribo germânica que se estabeleceu em grande parte da Europa entre o terceiro e o quinto século dC. $\mathrm{Na}$ arquitetura, o termo se refere a um renascimento (ou mais precisamente uma reconstrução cultural) de uma estética medieval que esteve em voga na Grã-Bretanha entre o início do século XVIII e o final do século XIX. Tais reconstruções de uma versão um tanto fantasiada do passado (combinadas com uma ideia de tribos germânicas "bárbaras") servem de contexto para o surgimento do gótico como modo literário. (SMITH, 2007, p. 2, tradução nossa) ${ }^{1}$
\end{abstract}

Talvez em parte devido ao forte apelo junto ao leitorado da combinação de elementos presentes neste universo de reconstruções relativamente fantasiadas da realidade, algumas obras góticas anglófonas alcançaram imensa popularidade para além de suas localidades e contextos históricos de origem, tornando-se best sellers no Brasil e em outras nações por várias gerações. Ademais, o gênero gótico vem sendo revisitado ao decorrer dos anos, ampliando consequentemente o seu público leitor na atualidade mesmo para obras escritas ainda no século XIX.

Provavelmente esta constante popularidade das obras góticas tenha sido o motivador para que Clarice Lispector fosse contratada para traduzir, na década de 1970, três grandes representantes do gênero, os quais compõem o corpus de pesquisa deste artigo: Tales of the Grotesque and Arabesque, de Edgar Allan Poe (lançado como volume em 1840 embora as histórias tenham sido publicadas individualmente em ocasiões anteriores, e comercializado no Brasil com os títulos Histórias extraordinárias e Histórias extraordinárias de Allan Poe); The picture of Dorian Gray, de Oscar Wilde (publicado em 1890 e traduzido por Lispector como $O$ retrato de Dorian Gray); e Interview with the vampire, de Anne Rice (lançado originalmente em 1976 e intitulado Entrevista com o vampiro no Brasil). As traduções clariceanas destes volumes serão analisadas aqui sob uma perspectiva descritiva, considerando concomitantemente elementos preliminares à publicação do texto e dimensões macroestruturais e microestruturais dos mesmos, conforme sugerido por Lambert e van Gorp (1985).

Conforme já indicado, as três obras foram traduzidas e/ou adaptadas por Lispector em uma curta janela temporal (as obras de Poe e Wilde afirmam em suas capas terem sido traduzidas e adaptadas pela autora, aspecto que por si só renderia um estudo à parte e não será abordado aqui). A tradução dos escritos de Wilde se deu inicialmente em 1974; a obra de Rice foi trazida ao Brasil no mesmo ano em que foi lançada no exterior, 1976; e, embora não seja

\footnotetext{
1 "The word 'Gothic' means different things in different contexts. The Goths were a Germanic tribe who settled in much of Europe from the third to the fifth centuries $A D$. In architecture the term refers to a revival (more accurately a cultural reconstruction) of a medieval aesthetic that was in vogue in Britain from the early eighteenth to the late nineteenth century. Such reconstructions of a somewhat fantasised version of the past (combined with a sense of 'barbaric' Germanic tribes) provide a context for the emergence of Gothic as a literary mode" (SMITH, 2007, p. 2).
} 
possível determinar com clareza o ano da primeira publicação da tradução clariceana para os escritos de Poe, informações paratextuais e extratextuais dão a entender que esta ocorreu entre 1973 e 1977 (é mencionada na edição consultada uma lei de direitos sobre a publicação datando de dezembro de 1973, e Lispector faleceu em 1977). A tradução destes textos no Brasil, portanto, se deu numa janela de no máximo quatro anos, embora sua publicação originalmente tenha se espaçado por quase um século e meio.

É necessário considerar a possibilidade de que a proximidade das datas de lançamento destes livros no Brasil e o fato destes três textos terem passado pelas mãos de Clarice Lispector e não de outros tradutores menos prestigiados possam ser mais do que meras coincidências, particularmente quando se leva em conta a enorme significância destas três obras ao pensar retrospectivamente o gênero gótico como um todo. Um fato que serve para exemplificar a relevância dos três títulos é que The handbook to Gothic literature, uma importante obra de referência sobre a temática, contém entradas individuais substantivas para cada uma das obras sendo aqui consideradas, num universo bastante limitado com relação a obras em si, mostrando o quanto estes livros são icônicos para a literatura gótica - ver Mulvey-Roberts (1998).

A hipótese inicial adotada para a análise das três traduções consideradas foi de que, por conta da proximidade temporal de suas publicações e também devido ao fato de Clarice Lispector se auto-afirmar minuciosa ao traduzir, haveriam elementos comuns que poderiam delinear um único projeto tradutório clariceano para a tradução de obras góticas. Para confirmação ou refutação desta hipótese, elementos microestruturais de trechos de cada tradução foram analisados. $\mathrm{Na}$ tradução da obra de Poe considerou-se a totalidade do primeiro conto apresentado, O gato preto (que vai das páginas 09 a 17). No livro de Wilde, foi considerado todo o primeiro capítulo (páginas 11 a 19). E, por fím, um número equivalente de páginas da primeira parte do texto de Rice foi considerado, indo da página 11 à 19 .

Em uma primeira leitura dos trechos eleitos para análise chama a atenção a percepção de que os textos trazem um registro consideravelmente alto. Esta impressão inicial, antes de uma análise detalhada do corpus, surpreende por não estar em clara consonância com o estilo de escrita de Lispector, o qual, segundo a própria autora, é permeado pela fluência, que em tese se oporia a um texto mais formal: "Eu, o autor deste livro, estou sendo tomado por mil demônios que escrevem dentro de mim. Esta necessidade de fluir, ah, jamais parar de fluir" (LISPECTOR, 1978, p.74). Embora Gonçalves (2006), em um estudo que engloba a tradução de um dos contos de Poe realizada por Lispector, afirme que a autora reconta aquela história em um tom mais coloquial que o original, no conto $O$ gato preto do mesmo autor e no mesmo volume a coloquialidade não salta aos olhos do leitor. A investigação do registro e da semelhança ou diferença dele entre as obras consideradas, portanto, assumiu lugar de destaque na análise proposta.

Falar, porém, em registro elevado sem uma proposta mais sistematizada de análise acaba por tornar todo o debate proposto demasiadamente abstrato. Assim sendo, optou-se por adotar aqui alguns elementos que são claros indicativos de registro alto na língua portuguesa brasileira na opinião de linguistas renomados, conforme já delineado em Hanes (2015): a utilização de ênclises, mesóclises, futuro sintético, pretérito-mais-que perfeito, e o uso do verbo haver com seus diferentes sentidos. Serão ainda acrescentados a esta lista itens lexicais de uso pouco disseminado para a análise em tela. As três amostras das obras consideradas são, portanto, aqui vistas com estes elementos balizadores para possível detecção de uma real elevação do registro. 
Considerando estes critérios, a tradução de $O$ gato preto traz, já em sua epígrafe um elemento pouco usual em boa parte do Brasil, que é a utilização de conjugações verbais na segunda pessoa do singular (tu). Este elemento dá ao texto um tom poético e/ou datado. $\mathrm{O}$ uso de outras construções como "fugia apavorado à minha aproximação" (p. 12) e "voltei à casa" (p. 12) (em lugar de para casa) reforçam o tom formal do texto. Com relação aos cinco elementos específicos eleitos como indicadores de registro alto, quatro deles estão presentes no trecho analisado: o futuro sintético (somente um caso), o pretérito-mais-que-perfeito (usado em 18 ocasiões), 36 ocorrências de ênclise, e nove casos do verbo haver.

O retrato de Dorian Gray também traz os mesmos quatro indicativos de registro alto observados na tradução da obra de Poe: nove usos de futuro sintético, quatro do pretérito maisque-perfeito, 27 ênclises e oito ocorrências do verbo haver. Ademais, construções como "Pedi a lady Brrandon que mo apresentasse" (p. 13), com a construção pronominal arcaica e a referência a uma lady no sentido nobiliárquico do termo servem, como no caso de Poe, para dar um ar arcaico ao texto.

Em Entrevista com o vampiro, somente três dos elementos específicos elencados foram observados, mas dois deles em grande número: foram contados três casos de futuro sintético somente, porém 21 usos do verbo haver e 44 ocorrências de ênclises na curta amostra considerada. Mais uma vez o texto traz, ainda, combinações de itens lexicais que remetem ao passado e a um tom mais formal, tais como o uso pronominal em "Não há nada de errado consigo" (p. 19, sendo usado por um padre), e "virando-se de modo a que o menino pudesse ver seu perfil" (p. 11), uma construção rebuscada que, assume-se, seria facilmente simplificável para Lispector se esta fosse sua intenção.

Os números apresentados atestam o porquê de todos os três textos à primeira vista terem sido considerados exemplos de registro alto, diante da ocorrência de estruturas que, quando se repetem demasiadamente, servem como artifício para um escritor ou tradutor capacitado (como no caso de Lispector) na criação de seu texto, visando o cumprimento de determinado objetivo. A relativa uniformidade nos pontos observados nas três obras, como a constante abundância de ênclises, também atesta que muito provavelmente não se trata de um uso de língua improvisado, mas de algo bem pensado e considerado.

Mas por que Clarice Lispector, que tanto prezava pela fluência na sua escrita, teria intencionalmente elevado o registro de suas traduções de obras góticas? Uma possibilidade seria evidenciada pelos poucos exemplos mencionados acima: o desejo de transmitir ao leitor o fato de que estes textos pertencem a um outro momento histórico, ou seja, que foram escritos há muitíssimos anos. Mesmo o texto de Rice, uma obra mais recente, representa o discurso de um personagem vampiro que, por conta de sua imortalidade, já era adulto no ano de 1791.

E a complexidade do uso de língua vai para além desta questão temporal: o registro é claramente mais elevado para diferentes personagens, marcando assim suas diferentes personalidades, idades, funções sociais. Em O retrato de Dorian Gray, o artista e idealista Basil Hallward se utiliza de um registro mais formal do que o boêmio e inconsequente lorde Henry Wotton. Em Entrevista com o vampiro, Louis adota um registro marcadamente mais formal do que aquele do jovem que o entrevista, nascido muitos e muitos anos após ele; e, na mesma obra, o padre do passado de Louis, que provavelmente viveu no final do século XVIII, também utiliza a construção pronominal "consigo" já mencionada acima, um elemento presente até hoje no português europeu, mas já há muito tempo abolido do português brasileiro.

A importância dada à voz dos personagens e, consequentemente, à voz do próprio narrador (que, em última instância e em consonância com Genette (1983) é obviamente aquele 
que de fato conta a história) está na verdade de acordo com o que se percebe na escrita autoral de Lispector. Considerando-se brevemente por exemplo os dois primeiros contos de Laços de família (2007), é possível perceber que no primeiro deles, "Devaneio e embriaguez duma rapariga", que se passa ao redor de uma personagem lusitana, o discurso da personagem principal e mesmo a voz do narrador acompanham o uso da língua portuguesa europeia. Por outro lado, em "Amor", que aparentemente trata de situações cotidianas da vida da dona de casa Ana (apesar de o texto se desenrolar em complexidade para muito além disto), o uso da língua é bastante pautado no português brasileiro coloquial, embora elementos de registro alto também se façam presentes.

A cuidadosa adoção do uso de língua nas traduções analisadas aqui está também em consonância com as próprias declarações de Clarice sobre o tema, particularmente no que toca a tradução de diálogos. Gomes (2004) compartilha com seus leitores as palavras daquela autora sobre a tradução de diálogos em peças teatrais, conforme publicado em edição da Revista Jóia em maio de 1968: "E a exaustiva leitura da peça em voz alta para podermos sentir como soam os diálogos? Estes têm que ser coloquiais: de acordo com as circunstâncias, ora mais ou menos cerimoniosos, ora mais ou menos relaxados." (GOMES, 2004, p. 42). Exatamente o que se observa, portanto, nas traduções das obras góticas analisadas. Neste sentido, Clarice Lispector demonstra compreender o que afirma Schiavi: "uma tradução é diferente de um original pois também contém a voz do tradutor, que em parte substitui a voz do autor e em parte é autônoma. Esta voz cria um relacionamento privilegiado com os leitores da tradução" (SCHIAVI, 1996, p. 3 , tradução nossa). ${ }^{2}$

A hipótese levantada de que seria possível perceber uma uniformidade e um projeto tradutório na abordagem de Lispector ao traduzir textos góticos se confirma: nas três obras notou-se a prevalência de um registro elevado, o qual dá pistas de ser parte de um planejamento da tradutora Clarice Lispector, resultando em um texto que pudesse transportar o leitor para uma época remota e para a consequente atmosfera dos textos traduzidos.

É possível notar que as convicções de Lispector acerca de sua escrita autoral tinham sim influência no seu modo de traduzir, mas não no sentido que se esperaria, ou seja, não simplesmente interferindo e transformando qualquer texto em um texto clariceano. O que se nota é que sua prática de abordar diferentemente os diferentes em sua escrita se estende para sua tradução, indo na prática, já naquele momento, contra aquela concepção histórica, questionada décadas depois da morte de Lispector por Hermans, acerca do que seria um bom tradutor: "Tradutores são bons tradutores se e quando se fazem desaparecer". (HERMANS, 1996, p. 44). ${ }^{3}$ Lispector se mostra vanguardista, muito presente em suas traduções de obras literárias góticas, demonstrando que, mesmo ao utilizar aquela que era uma abordagem predominante na tradução naquele momento histórico, ou seja, a elevação do registro em obras traduzidas, ainda era possível deixar suas marcas autorais denotando um projeto tradutório comprometido e até mesmo subversivo.

\footnotetext{
2 "A translation is different from an original in that it also contains the translator's voice, which is in part standing in for the author's and in part autonomous. This voice creates a privileged relationship with the readers of translation" (SCHIAVI, 1996, p. 3).

3 "Translators are good translators if and when they have spirited themselves away" (HERMANS, 1996, p. 44).
} 


\section{Referências}

FERREIRA, R. M. C. Traduzir pode correr o risco de não parar nunca: Clarice Lispector tradutora (um arquivo). Revista Belas Infiéis, v. 2, n. 2, p. 175-204, 2013. Disponível em: http://periodicos.unb.br/index.php/belasinfieis/article/view/10630/769. Acesso em: 13 nov. 2014.

GENETTE, G. Narrative discourse: an essay in method. Tradução: Jane E. Lewin. New York: Cornell University Press, 1983.

GOMES, A. L. Entre espelhos e interferências: a problemática da tradução para Clarice Lispector. Via Atlântica, n. 7, p. 39-52, 2004. Disponível em:

http://www.revistas.usp.br/viaatlan tica/article/view/49784. Acesso em: 12 out. 2014.

GONÇALVES, F. Tradução, interpretação e recepção literária: manifestações de Edgar Alan Poe no Brasil. 2006. 141 f. Dissertação (Mestrado em Letras) - Programa de PósGraduação em Letras, Universidade Federal do Rio Grande do Sul, Porto Alegre, 2006. Disponível em: http://www.lume.ufrgs.br/handle/10183/7123. Acesso em: 01 ago. 2020.

HANES, V. L. L. The language of translation in Brazil: written representations of oral discourse in Agatha Christie. 2015. 308 f. Tese (Doutorado em Estudos da Tradução) Programa de Pós-Graduação em Estudos da Tradução, Universidade Federal de Santa Catarina, Florianópolis, 2015. Disponível em:

https://repositorio.ufsc.br/handle/123456789/158404?show=full. Acesso em: 01 ago. 2020.

HERMANS, T. The translator's voice in translated narrative. Target International Journal of Translation Studies, v. 8, n. 1, p. 23-48, 1996.

LAMBERT, J.; VAN GORP, H. On describing translations. In: HERMANS, T. (org.). The manipulation of literature: studies in literary translation. London: Croom Helm, 1985. p. 42-53.

LISPECTOR, C. Laços de família. Rio de Janeiro: Rocco, 2007.

LISPECTOR, C. Um sopro de vida (pulsações). Rio de Janeiro: Rocco, 1978.

MOSER, B. Clarice: uma biografia. Companhia das Letras, 2017.

MULVEY-ROBERTS, M. (org.). The handbook to Gothic literature. Nova York: NYU Press, 1998.

OLIVEIRA, A. Representações monstruosas em A paixão segundo G.H. de Clarice Lispector. 2012. 116 f. Dissertação (Mestrado em Letras) - Programa de Pós-Graduação em Letras, Universidade Federal de Sergipe, São Cristóvão, 2012.

POE, E. A. Histórias extraordinárias de Allan Poe. Tradução e adaptação de Clarice Lispector. Rio de Janeiro: Ediouro, 1998. 
PROSPERO, C. L. A literatura do medo nos contos de Clarice Lispector. In: XI CONGRESSO INTERNACIONAL DA ABRALIC, 2008, São Paulo. Anais. São Paulo: USP, 2008.

QUEIROGA, M. G. A voz da tradutora Clarice Lispector em livros infantojuvenis do gênero aventura. 2014. 224 f. Tese (Doutorado em Estudos da Tradução) - Programa de Pós-Graduação em Estudos da Tradução, Universidade Federal de Santa Catarina, Florianópolis, 2014. Disponível em:

https://repositorio.ufsc.br/bitstream/handle/123456789/128950/332222.pdf?sequence=1. Acesso em: 30 jul. 2020.

RICE, A. Entrevista com o vampiro. Rio de Janeiro: Rocco, 1995.

SCHIAVI, G. There is always a teller in a tale. Target International Journal of Translation Studies, v. 8, n. 1, p. 1-22, 1996.

SMITH, A. Gothic literature. Edinburgh: Edinburgh University Press, 2007.

WILDE, O. O retrato de Dorian Gray. Tradução e adaptação de Clarice Lispector. Rio de Janeiro: Ediouro, 2006.

Recebido em: 24 de outubro de 2020 Aceito em: 10 de novembro de 2020 Publicado em Dezembro de 2020 